\title{
Photosynthetic and yield performance of wild barley (Hordeum vulgare ssp. spontaneum) under terminal heat stress
}

\author{
F. BAHRAMI, A. ARZANI ${ }^{+}$, and M. RAHIMMALEK \\ Department of Agronomy and Plant Breeding, College of Agriculture, Isfahan University of Technology, Isfahan \\ 8415683111, Iran
}

\begin{abstract}
Terminal heat stress is one of the major constraints of cereal production. A two-year field investigation was performed to assess the response of Hordeum vulgare ssp. spontaneum genotypes to terminal heat stress using gas-exchange parameters, photosystem efficiency, proline accumulation, cell membrane leakage, and grain yield traits. Results of analysis of variance revealed the significant effects of heat stress $(\mathrm{E})$, genotype $(\mathrm{G})$, and $\mathrm{G} \times \mathrm{E}$ on the studied traits. The results of linear regression analysis showed that yield loss was inversely correlated with the maximum quantum yield of PSII photochemistry $\left(\mathrm{F}_{\mathrm{v}} / \mathrm{F}_{\mathrm{m}}\right)$ and chlorophyll content. Path-coefficient analysis revealed that high Chl contents were either directly related to the grain yield or indirectly through the higher net photosynthetic rate and higher $F_{v} / F_{m}$ values under high temperatures at the reproductive growth stage. Overall, the adapted wild genotypes exhibited physiological mechanisms capable of sustainable maintaining their yield capacity and plasticity flow, which could be exploited by crossing with cultivated barley to introgress heat tolerance.
\end{abstract}

Additional key words: abiotic stress; climate changes; genetic diversity, high-temperature stress; photosynthetic capacity; physiology.

\section{Introduction}

Thermal stress is a major abiotic stress likely to be worsening under global warming conditions (Bita and Gerats 2013, Schauberger et al. 2017). Based on climate model predictions, the global mean temperature will rise by $1-4^{\circ} \mathrm{C}$ above the present temperature by the end of the twenty-first century (Driedonks et al. 2016). Effects of heat stress on crops depend on heat duration and intensity, rate of temperature rise, and plant developmental stage (Wahid et al. 2007). Furthermore, plant growth and development can be affected by high temperatures due to vulnerability of plant architecture as well as its physiological and reproductive processes (Driedonks et al. 2016). The predicted average temperature rise of $3-4^{\circ} \mathrm{C}$ is expected to reduce crop production in the Middle East by 25-35\% (Ortiz et al. 2008). Crop yield could, indeed, be affected by heat stress by inducing pollen sterility and seed abortion during the reproductive growth stage (Barnabás et al. 2008, Rezaei et al. 2010). Reduced crop productivity due to high temperatures during the reproductive stage has been reported in many cereals, such as barley (Klink et al. 2014), wheat (Dias et al. 2011, Dwivedi et al. 2017), and rice (Shi et al. 2016).

Despite the economic importance of cultivated barley (Hordeum vulgare ssp. vulgare) as a major cereal crop worldwide, little is known about its thermal-tolerance mechanisms. Wild barley, the $H$. vulgare ssp. spontaneum L. species, is a widely distributed one (Thormann et al. 2016) that is cross-compatible with its immediate descendant, the domesticated barley subspecies. The progenitor of cultivated barley, $H$. vulgare ssp. spontaneum, primarily originated from Irano-Turanian and Mediterranean regions before it flowed outward as curtained stable inhabitants in desert ecosystems (Harlan and Zohary 1966). Phenotypic plasticity in $H$. vulgare ssp. spontaneum is regarded as a feature that substantially motivated the spread and persistence of the plants in various environmental conditions across almost all western Iran; hence, it is proposed as a heat and drought-tolerant species (Arzani and Ashraf 2016). Genetic diversity analysis of 51 $H$. spontaneum populations using molecular markers revealed the effective roles of temperature and precipitation as selective pressures in the Fertile Crescent on the adaptation of wild barley (Hübner et al. 2009).

In general, sustainability in leaf gas exchanges and photosystem efficiency are directly related to heat tolerance in crop plants (Wahid et al. 2007, Bita and Gerats 2013). Brestic and Živčák (2013) reported that temperature increase to $37^{\circ} \mathrm{C}$ could lead to reduced stomatal

Received 16 January 2018, accepted 1 June 2018.

${ }^{+}$Corresponding author; phone: +98 311 3913453, fax: +98 311 3912254, e-mail: a_arzani@cc.iut.ac.ir

Abbreviations: $\mathrm{Chl}$ - chlorophyll; $\mathrm{C}_{\mathrm{i}}$ - intercellular $\mathrm{CO}_{2}$ concentration; $\mathrm{F}_{0}$ - minimum fluorescence intensity; $\mathrm{F}_{\mathrm{m}}$ - maximum fluorescence intensity; $\mathrm{F}_{\mathrm{v}} / \mathrm{F}_{\mathrm{m}}$ - maximum quantum yield of PSII photochemistry; $g_{\mathrm{s}}$ - stomatal conductance; MSI - membrane stability index; $P_{\mathrm{N}}-$ net photosynthetic rate.

Acknowledgement: This work was supported by funds from the Iran National Science Foundation (INSF) under Grant No. 96002328. 
conductance $\left(g_{\mathrm{s}}\right)$. It is well-established that leaf photosynthesis, as the most heat-sensitive metabolic process, can be interrupted under high temperatures (Wang et al. 2015). The PSII and the carbon fixation by Rubisco are the prime targets of thermal stress on the plant photosynthetic apparatus (Allakhverdiev et al. 2008, Ashraf and Harris 2013, Oukarroum et al. 2016). Furthermore, chlorophyll (Chl) fluorescence has been found a reliable physiological parameter not only for measuring PSII efficiency, but also determining damage to the photosynthetic apparatus due to heat stress (Allakhverdiev et al. 1997, Allakhverdiev 2011, Jedmowski et al. 2015). Maximum quantum yield of PSII photochemistry $\left(\mathrm{F}_{\mathrm{v}} / \mathrm{F}_{\mathrm{m}}\right)$ has been widely applied as a selection criterion for heat-tolerant genotypes in crops (Sharma et al. 2012, 2015). The reduced Chl content has been correlated with damage to the thylakoid membrane with the subsequent reduction in photosynthesis due to heat stress (Wang et al. 2015). Gupta et al. (2015) reported that high temperature at a grain-filling stage would lead to reductions in photosynthetic capacity, Chl content, and grain yield in wheat genotypes. Proline accumulation, which is involved in cellular osmoregulation and protection of cellular structures against increased temperatures by cell water balance conservation and stabilization of biological membranes, is an important adaptive response in crops exposed to high temperatures (Wahid et al. 2007, Bita and Gerats 2013). Accumulation of proline has been reported to increase in response to heat stress in wheat genotypes (Dhyani et al. 2013, Truong et al. 2017).

Effective exploitation of heat-tolerant genetic resources in breeding crop plants is an urgent priority in the context of genetic erosion and climate change scenarios. At the end of the day, the fulfillment of this goal depends on a number of major factors such as crossability as well as both intra- and inter-genomic chromosome pairing in hybrids of domesticated and wild species. Thus, the use of spontaneum wild subspecies (H. vulgare ssp. spontaneum) seems meaningful as successful achievements in these aspects could likely lead to beneficial outcomes for improving heat-tolerant barley cultivars. The complete genome homology between cultivated barley $H$. vulgare ssp. vulgare $(2 n=2 x=14, \mathrm{HH})$ and $H$. vulgare ssp. spontaneum $(2 n=2 x=14, \mathrm{HH})$ as well as adaptation of the wild subspecies to harsh climatic conditions, including high temperatures, could be quoted as the reasons for the successful hybridization and subsequent gene introgression of the thermal-tolerance attribute. Given the seriousness of global warming that requires enhanced heat tolerance through improved photosynthesis as the main goal in many $\mathrm{C}_{3}$ crops and considering the limited data available on physiological thermal-tolerance responses in wild barley under field conditions, the current study was performed to (1) investigate the physiological responses of $H$. vulgare ssp. spontaneum genotypes to post-anthesis high-temperature stress and (2) determine an adaptation strategy for wild genotypes under field conditions.

\section{Materials and methods}

A total of 49 barley genotypes including $45 \mathrm{H}$. spontaneum genotypes collected from western Iran (namely Ilam, Kermanshah, Lorestan, Kordestan, and West Azarbaijan provinces) and four barley cultivars comprising 'Mona', 'Reyhan', 'Nosrat', and 'Fajr30' (Table 1S, supplement) were grown in two consecutive years (2015-2016 and 2016-2017) at the research farm of Isfahan University of Technology located at Lavark, Najaf-Abad, Iran $(40 \mathrm{~km}$ south west of Isfahan, $32^{\circ} 32^{\prime} \mathrm{N}, 51^{\circ} 23^{\prime} \mathrm{E}, 1,630 \mathrm{~m}$ a.s.l. with a mean annual precipitation of $149 \mathrm{~mm}$ ). The soil type of the experimental field was silty clay loam, typic Haplargids of the arid tropic, with $\mathrm{pH}$ 7.3-7.8.

Under both trial conditions (normal and heat stress), crop management was carried out uniformly with fertilizer application, weed control, and irrigation to avoid drought conditions. All the physiological studies were performed at the grain-filling stage on flag leaves for both conditions.

Table presents details of the sowing dates and phonological stage of the genotypes in the two growing seasons. A square lattice design $(7 \times 7)$ with two replications was used for each of the two sowing dates including October (normal) and January (terminal heat stress). The seeds were planted at 4-m long plots comprising five rows spaced $30 \mathrm{~cm}$ apart.

Leaf gas-exchange measurements were accomplished on intact flag leaves at the grain-filling stage. Net photosynthetic rate $\left(P_{\mathrm{N}}\right)$, stomatal conductance $\left(g_{\mathrm{s}}\right)$, and intercellular $\mathrm{CO}_{2}$ concentration $\left(C_{\mathrm{i}}\right)$ were recorded using an

Temperature variations of experimental site at different growth stages of barley genotypes grown under normal and heat stress conditions.

\begin{tabular}{|c|c|c|c|c|c|c|c|c|c|}
\hline \multirow[t]{3}{*}{ Time } & \multirow[t]{3}{*}{ Year } & \multicolumn{6}{|c|}{ Temperature $\left[{ }^{\circ} \mathrm{C}\right]$} & \multicolumn{2}{|c|}{ Relative humidity [\%] } \\
\hline & & \multicolumn{2}{|l|}{ Minimum } & \multicolumn{2}{|c|}{ Maximum } & \multicolumn{2}{|l|}{ Mean } & \multirow[b]{2}{*}{$\begin{array}{l}\text { Normal } \\
\text { sown }\end{array}$} & \multirow[b]{2}{*}{$\begin{array}{l}\text { Late } \\
\text { sown }\end{array}$} \\
\hline & & $\begin{array}{l}\text { Normal } \\
\text { sown }\end{array}$ & $\begin{array}{l}\text { Late } \\
\text { sown }\end{array}$ & $\begin{array}{l}\text { Normal } \\
\text { sown }\end{array}$ & $\begin{array}{l}\text { Late } \\
\text { sown }\end{array}$ & $\begin{array}{l}\text { Normal } \\
\text { sown }\end{array}$ & $\begin{array}{l}\text { Late } \\
\text { sown }\end{array}$ & & \\
\hline \multirow[t]{2}{*}{ Sowing } & 2015-16 & 12.4 & 5.0 & 21.0 & 14.8 & 16.7 & 9.9 & 63 & 65 \\
\hline & $2016-17$ & 9.8 & -0.6 & 22.2 & 14.6 & 16.0 & 7.0 & 40 & 30 \\
\hline \multirow[t]{2}{*}{ Anthesis } & 2015-16 & 5.0 & 19.2 & 20.4 & 29.4 & 12.7 & 24.3 & 35 & 30 \\
\hline & 2016-17 & 2.8 & 11.0 & 19.0 & 23.4 & 10.9 & 17.2 & 40 & 57 \\
\hline \multirow[t]{2}{*}{ Maturity } & $2015-16$ & 14.0 & 21.6 & 24.2 & 35.1 & 19.1 & 28.3 & 57 & 19 \\
\hline & 2016-17 & 11.0 & 22.4 & 27.6 & 37.6 & 19.3 & 30.0 & 42 & 9 \\
\hline
\end{tabular}


Sowing dates and phonological stages of 49 barley genotypes grown in the field conditions.

\begin{tabular}{lllllll}
\hline & Sowing date & & \multicolumn{2}{c}{ Time to anthesis [d] } & \multicolumn{2}{c}{ Time to maturity [d] } \\
Year & Normal sown & Late sown & Normal sown & Late sown & Normal sown & Late sown \\
\hline 2015-2016 & 23.10 .2015 & 04.01 .2016 & 163 & 123 & 199 & 151 \\
2016-2017 & 23.10 .2016 & 03.01 .2017 & 162 & 121 & 197 & 149 \\
\hline
\end{tabular}

open-system portable infrared gas analyzer ( $L C A-4 A D C$, Analytical Development Company, Hoddesdon, UK). Measurements were made under constant conditions at temperatures in the range of $25-30^{\circ} \mathrm{C}$, a relative humidity of $50-60 \%$, a light intensity in the range of 1,400-1,700 $\mu \mathrm{mol}\left(\right.$ photon) $\mathrm{m}^{-2} \mathrm{~s}^{-1}$, and $\mathrm{a} \mathrm{CO}_{2}$ concentration of $400 \mu \mathrm{mol}$ $\mathrm{mol}^{-1}$ from 10:00 to $12: 00 \mathrm{~h}$ for two consecutive days.

Chl fluorescence parameters were measured in the dark using a Chl fluorometer (OS-30p, Opti-Science, London). Minimum $\left(\mathrm{F}_{0}\right)$ and maximum $\left(\mathrm{F}_{\mathrm{m}}\right)$ fluorescence intensity were measured in dark-adapted leaves using leaf clips (FL-DC, Opti-Science). In addition, maximum quantum yield of PSII photochemistry $\left(\mathrm{F}_{\mathrm{v}} / \mathrm{F}_{\mathrm{m}}\right)$ was calculated $\left(F_{m}-F_{0}\right) / F_{m}$ when all PSII reaction centers were fully oxidized. Chl fluorescence measurements were made on the fully expanded flag leaves of barley plants at the grain-filling stage. All the measurements were conducted on field-grown plants under natural sunlight with PPFD $>1,200 \mu \mathrm{mol}$ (photon) $\mathrm{m}^{-2} \mathrm{~s}^{-1}$ at the temperature in the range of $25-30^{\circ} \mathrm{C}$.

Chl and carotenoids (Car) were extracted in acetone 80\% according to the standard method of Lichtenthaler (1983) using fresh leaves at the grain-filling stage. The absorbance of the solutions was measured at 663,646 , and $470 \mathrm{~nm}$ using a UV/visible spectrophotometer (U-1800, Hitachi, Japan). Concentrations (C) were then calculated and expressed as $\mathrm{mg} \mathrm{g}^{-1}(\mathrm{FM})$ using the following equations:

Chl $a: \mathrm{C}_{\mathrm{a}}=12.21 \times \mathrm{A}_{663}-2.81 \times \mathrm{A}_{646} \times \mathrm{V} / 1,000 \times \mathrm{W}$

Chl $b: \mathrm{C}_{\mathrm{b}}=20.13 \times \mathrm{A}_{646}-5.03 \times \mathrm{A}_{663} \times \mathrm{V} / 1,000 \times \mathrm{W}$

Car: $\mathrm{C}_{\mathrm{x}+\mathrm{c}}=\left[\left(1,000 \times \mathrm{A}_{470}\right)-\left(1.9 \mathrm{C}_{\mathrm{a}}\right)-\left(63.14 \mathrm{C}_{\mathrm{b}}\right)\right] /$

$214 \times \mathrm{V} / 1,000 \times \mathrm{W}$

where $\mathrm{A}$ is absorbance, $\mathrm{V}$ is the volume of acetone ( $\mathrm{ml}$ ), and $\mathrm{W}$ is the fresh mass $(\mathrm{g})$.

Proline content was measured according to the ninhydrin method of Bates et al. (1973) using fresh leaves at the grain-filling stage. Leaf samples $(0.2 \mathrm{~g})$ were homogenized in $10 \mathrm{ml}$ of $3 \%$ aqueous sulfosalicylic acid centrifuged for $10 \mathrm{~min}$ at $10,000 \mathrm{rpm}$. This supernatant was reacted with $2 \mathrm{ml}$ of acid ninhydrin and $2 \mathrm{ml}$ of glacial acetic acid before being boiled at $96^{\circ} \mathrm{C}$ for $1 \mathrm{~h}$. After stopping the reaction in an ice bath, the reaction mixture was extracted in $4 \mathrm{ml}$ of toluene before the absorbance of the pink-red upper phase was measured at $520 \mathrm{~nm}$ using UV-visible spectrophotometer (U-1,800, Hitachi, Japan) against toluene blank. The proline content was finally calculated using the standard curve and expressed in $\mathrm{mg} \mathrm{g}^{-1}(\mathrm{FM})$.

Cell membrane stability: Leaf electrolyte leakage was estimated at the grain-filling stage by taking $0.2 \mathrm{~g}$ of fresh leaves in tubes containing $10 \mathrm{ml}$ of double distilled water in a water bath at $40^{\circ} \mathrm{C}$ for $30 \mathrm{~min}$, before the electrical conductivity of the solution was recorded on a conductivity bridge $\left(\mathrm{C}_{1}\right)$. The samples were subsequently boiled at $100^{\circ} \mathrm{C}$ at a boiling water bath for $10 \mathrm{~min}$ and their conductivity was measured on a conductivity bridge $\left(\mathrm{C}_{2}\right)$. The membrane stability index was then calculated as MSI $=\left[1-\left(C_{1} / C_{2}\right)\right] \times 100($ Sairam 1994)

Grain yield: Grains were harvested from the three middle rows in the normal (May 2016) and heat stress (June 2017) treatments, and the grain yield was determined and expressed as $\mathrm{kg} \mathrm{ha}^{-1}$.

Statistical analysis: The data were subjected to a combined analysis of variance (ANOVA) using the GLM procedure of $S A S$ software (Version 9.3, SAS Institute 2011). The efficiency of the lattice design was compared (tested) against that of randomized complete block design (RCBD) by calculating the ratio of the lattice mean square of error $\times 100 /$ RCBD mean square error for each trait. The results showed only slight gains in efficiency by using a lattice design rather than the RCBD for all the traits; hence, the RCBD design was used to analyze the data. Mean comparisons were carried out using the Fisher's leastsignificant difference $\left(\mathrm{LSD}_{5 \%}\right)$ test. Linear regression and path-coefficient analysis were also carried out to determine the relationship between grain yield loss and physiological variables using SPSS software.

Cluster analysis was accomplished based on physiological traits, grain yield, and grain yield loss via the Ward's method as a measure of similarity using SPSS statistics. The optimal number of clusters was estimated by $p$-value obtained from Hotelling's $T$-square $\left(T^{2}\right)$ test. Finally, group means obtained from the cluster analysis were compared using the Fisher's least-significant difference $\left(\mathrm{LSD}_{5 \%}\right)$ test.

\section{Results}

Combined ANOVA results showed that all the traits studied were significantly influenced by the environment (heat stress), genotype, and genotype $\times$ environment interaction (Table 1). However, no significant differences were found between the two study years in the traits studied except for $g_{s}$ and MSI. There were highly significant variations in the traits studied among the wild genotypes, whereas no significant differences were observed in the Chl content and $\mathrm{F}_{\mathrm{m}}$ among the four cultivars (Table 1).

Terminal heat stress caused significant reductions in $P_{\mathrm{N}}$ and $g_{s}$ but a significant increase in $C_{\mathrm{i}}$ of 49 barley genotypes studied. In contrast to normal conditions, in 


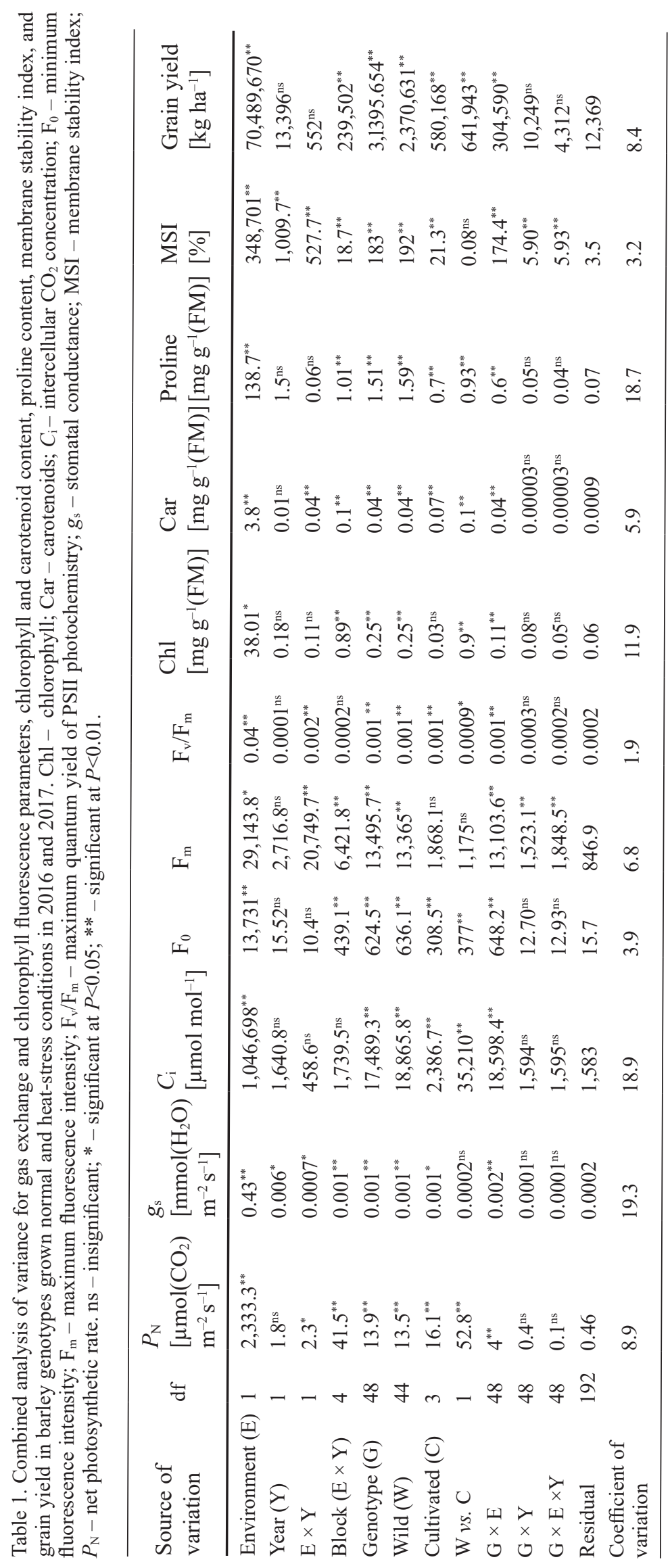


Table 2. Means of gas-exchange and chlorophyll fluorescence parameters, chlorophyll and carotenoid content, proline content, membrane stability index and grain yield in wild and cultivated barley genotypes grown under normal and heat stress field conditions. $\mathrm{Chl}$ - chlorophyll; $C_{\mathrm{i}}$ - intercellular $\mathrm{CO}_{2}$ concentration; $\mathrm{F}_{0}$ - minimum fluorescence intensity; $\mathrm{F}_{\mathrm{m}}$ - maximum fluorescence intensity; $\mathrm{F}_{\mathrm{v}} / \mathrm{F}_{\mathrm{m}}-$ maximum quantum yield of PSII photochemistry; $g_{\mathrm{s}}$ - stomatal conductance; MSI - membrane stability index; $P_{\mathrm{N}}-$ net photosynthetic rate. Means in each row under normal or stress conditions followed by the same letter are not statistically different at $P<0.01$.

\begin{tabular}{|c|c|c|c|c|}
\hline \multirow[b]{2}{*}{ Trait } & \multicolumn{2}{|l|}{ Normal } & \multicolumn{2}{|c|}{ Heat stress } \\
\hline & Wild & Cultivated & Wild & Cultivated \\
\hline$P_{\mathrm{N}}\left[\mu \mathrm{mol}\left(\mathrm{CO}_{2}\right) \mathrm{m}^{-2} \mathrm{~s}^{-1}\right]$ & $9.82^{b}$ & $12.10^{\mathrm{a}}$ & $5.24^{\mathrm{a}}$ & $3.94^{b}$ \\
\hline$g_{\mathrm{s}}\left[\mathrm{mmol}\left(\mathrm{H}_{2} \mathrm{O}\right) \mathrm{m}^{-2} \mathrm{~s}^{-1}\right]$ & $0.11^{\mathrm{b}}$ & $0.13^{\mathrm{a}}$ & $0.05^{\mathrm{a}}$ & $0.02^{\mathrm{b}}$ \\
\hline$C_{\mathrm{i}}\left[\mu \mathrm{mol} \mathrm{mol}^{-1}\right]$ & $162.67^{\mathrm{a}}$ & $114.50^{\mathrm{b}}$ & $259.58^{\mathrm{b}}$ & $290.31^{\mathrm{a}}$ \\
\hline $\mathrm{F}_{0}$ & $92.52^{\mathrm{b}}$ & $102.25^{\mathrm{a}}$ & $104.93^{\mathrm{b}}$ & $107.31^{\mathrm{a}}$ \\
\hline $\mathrm{F}_{\mathrm{m}}$ & $427.68^{b}$ & $472.88^{\mathrm{a}}$ & $410.80^{\mathrm{b}}$ & $451.43^{\mathrm{a}}$ \\
\hline $\mathrm{F}_{\mathrm{v}} / \mathrm{F}_{\mathrm{m}}$ & $0.780^{\mathrm{a}}$ & $0.779^{\mathrm{a}}$ & $0.763^{\mathrm{a}}$ & $0.716^{\mathrm{b}}$ \\
\hline Chl content $\left[\mathrm{mg} \mathrm{g}^{-1}(\mathrm{FM})\right]$ & $2.45^{\mathrm{a}}$ & $2.43^{\mathrm{a}}$ & $1.83^{\mathrm{a}}$ & $1.40^{\mathrm{b}}$ \\
\hline Carotenoid content $\left[\mathrm{mg} \mathrm{g}^{-1}(\mathrm{FM})\right]$ & $0.62^{\mathrm{a}}$ & $0.56^{\mathrm{b}}$ & $0.43^{\mathrm{a}}$ & $0.41^{\mathrm{a}}$ \\
\hline Proline content $\left[\mathrm{mg} \mathrm{g}^{-1}(\mathrm{FM})\right]$ & $0.86^{\mathrm{a}}$ & $0.87^{\mathrm{a}}$ & $2.11^{\mathrm{a}}$ & $1.81^{\mathrm{b}}$ \\
\hline MSI [\%] & $88.00^{\mathrm{a}}$ & $86.99^{\mathrm{a}}$ & $29.96^{\mathrm{a}}$ & $23.09^{\mathrm{b}}$ \\
\hline Grain yield $\left[\mathrm{kg} \mathrm{ha}^{-1}\right]$ & $1,507.11^{\mathrm{b}}$ & $4246.00^{\mathrm{a}}$ & $893.23^{\mathrm{b}}$ & $2,139.14^{\mathrm{a}}$ \\
\hline
\end{tabular}

which cultivated barley was superior with respect to $P_{\mathrm{N}}$ and $g_{\mathrm{s}}$, the mean values of $P_{\mathrm{N}}$ and $g_{\mathrm{s}}$ were higher in the wild genotypes than in the cultivated ones under heat stress treatment (Table 2). In addition, the photosynthetic rate ranged from 3.24 to $8.44 \mu \mathrm{mol}\left(\mathrm{CO}_{2}\right) \mathrm{m}^{-2} \mathrm{~s}^{-1}$ in the wild genotypes but from 2.21 to $5.68 \mu \mathrm{mol}\left(\mathrm{CO}_{2}\right) \mathrm{m}^{-2} \mathrm{~s}^{-1}$ in the four barley cultivars exposed to heat stress. The mean enhancement found in $C_{\mathrm{i}}$ due to heat stress was 175.81

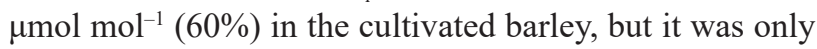
$96.91 \mu \mathrm{mol} \mathrm{mol}{ }^{-1}(37 \%)$ in the wild genotypes tested. The results of linear regression analysis between $P_{\mathrm{N}}$ and the grain yield loss in 45 wild genotypes indicated that the two traits were strongly negatively correlated $\left(R=-0.63^{* *}\right)$ under heat stress conditions.

Chl fluorescence parameters were significantly influenced by heat stress (Table 1). The values of $F_{m}$ and $\mathrm{F}_{\mathrm{v}} / \mathrm{F}_{\mathrm{m}}$ declined, while $\mathrm{F}_{0}$ increased as a result of heat stress. Although the genotypes studied (wild + cultivated) exhibited significant variations in their Chl fluorescence parameters, the cultivated genotypes did not vary signifi-

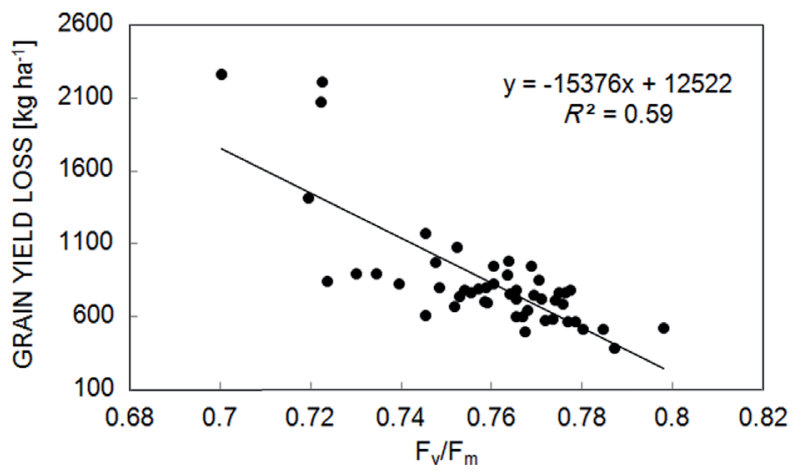

Fig. 1. Relationship between grain yield loss and maximum quantum yield of PSII $\left(\mathrm{F}_{\mathrm{v}} / \mathrm{F}_{\mathrm{m}}\right)$ of 49 barley genotypes under heat stress conditions. cantly in their $\mathrm{F}_{\mathrm{m}}$ (Table 1). Wild barley genotypes showed higher variations $(0.723-0.798)$ in their $F_{v} / F_{m}$ under heat stress conditions than that of the barley cultivars $(0.700$ 0.722). Accordingly, the cultivated genotypes experienced greater reductions in $\mathrm{F}_{\mathrm{v}} / \mathrm{F}_{\mathrm{m}}$ under heat stress than that of the wild ones (Table 2). In the current study, wild genotypes number $1,2,9$, and 22 exhibited the highest $F_{\mathrm{v}} / \mathrm{F}_{\mathrm{m}}$ values $(0.798,0.787,0.784$, and 0.780 , respectively) under heat stress. Moreover, linear regression analysis results showed a strongly negative correlation $\left(r=-0.84^{* *}\right)$ between $\mathrm{F}_{\mathrm{v}} / \mathrm{F}_{\mathrm{m}}$ and the grain yield loss (Fig. 1).

Total Chl and Car content underwent a significant decrease under heat stress as compared with normal conditions (Table 2). Total Chl content ranged from 1.54 to $2.32 \mathrm{mg} \mathrm{g}^{-1}(\mathrm{FM})$ in the wild genotypes and $1.32-1.48 \mathrm{mg}$ $\mathrm{g}^{-1}(\mathrm{FM})$ in the cultivated ones. Heat stress affected greatly total $\mathrm{Chl}$ in the cultivated genotypes when compared to the wild ones (Table 2). A high positive correlation was also found between total $\mathrm{Chl}$ and $P_{\mathrm{N}}$ under heat stress $\left(r=0.77^{* *}\right)$, while the total Chl content and grain yield loss exhibited a negative relationship $\left(r=-0.83^{* *}\right)$ under heat stress (Fig. 2).

Terminal heat stress led to significant $(P<0.01)$ increases in the leaf proline content (Table 1) ranged from 1.29 to $3.64 \mathrm{mg} \mathrm{g}^{-1}$ (FM) in wild barley and $1.64-2.35 \mathrm{mg}$ $\mathrm{g}^{-1}(\mathrm{FM})$ in cultivated ones. Compared to the cultivated genotypes, the wild ones displayed enhancements in their proline accumulation by $60 \%$ due to heat stress (Table 2 ). The highest proline accumulation was observed in the wild genotypes including 1, 4, 8, and 21 .

Mean of MSI values in the barley genotypes decreased significantly under heat stress (Table 1). MSI values ranged from 21.1 to $56.7 \%$ among the wild barley genotypes and from 22.3 to $25.4 \%$ among the cultivated ones under heat stress. The mean comparisons showed that MSI values in the wild genotypes under heat stress were higher than those 


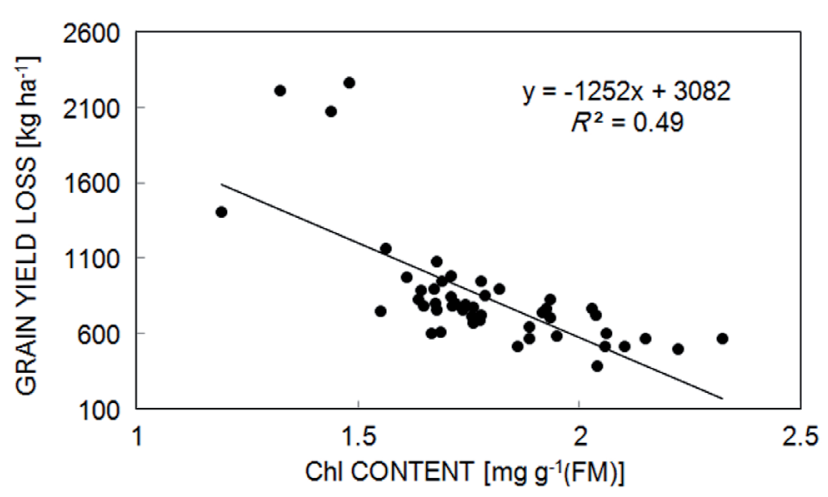

Fig. 2. Relationship between grain yield loss and chlorophyll (Chl) content of 49 barley genotypes under heat stress conditions.

in the four barley cultivars studied (Table 2). Moreover, the wild genotype 1,2 , and 41 with MSI reductions of 32, 36 , and $37 \%$, respectively, under heat stress exhibited the least membrane injury among the genotypes studied. A positive correlation was found between MSI and $P_{\mathrm{N}}$ under heat stress $\left(r=0.73^{* *}\right)$. Path coefficient analysis revealed both direct and indirect effects of physiological variables on the grain yield (Table 3 ). The results also showed that the total $\mathrm{Chl}$ content exhibited the maximum negative direct effect $(-0.46)$ on the grain yield loss in the wild barley genotypes followed by $P_{\mathrm{N}}(-0.35)$ and $\mathrm{F}_{\mathrm{v}} / \mathrm{F}_{\mathrm{m}}(-0.22)$ under high temperature.

Cluster analysis of the data obtained on the plants exposed to heat stress classified the genotypes into two groups, at a low Euclidean distance, which exactly corresponded to the two wild and cultivated barley subspecies (Fig. 3). The 45 wild genotypes were further divided into three groups at a high Euclidean distance, which comprised the genotypes 11,12 , and 22 . The cultivated barley genotypes exhibited much higher grain yield losses than that of the wild ones. Eleven wild barley genotypes categorized in the first group exhibited the highest values of $P_{\mathrm{N}}, g_{\mathrm{s}}$, and proline accumulation, MSI, grain yield, and grain yield loss among the wild genotypes. On the other hand, four cultivated genotypes exhibited the highest grain yield losses which might result from their lowest values of $P_{\mathrm{N}}, g_{\mathrm{s}}, \mathrm{F}_{\mathrm{v}} / \mathrm{F}_{\mathrm{m}}$, and total Chl content.

\section{Discussion}

High temperatures cause adverse physiological modifications and responses in plants including their photosynthesis, respiration, and interacting processes, especially in the reproductive organs. Winter small-grain cereals are predominantly affected by terminal heat stress, implying that temperature generally rises during the grain development period. Wild relatives of cultivated crops naturally furnish an indispensable gene pool for tolerance to abiotic stress (Arzani and Ashraf 2016). In their study of population structure, Hübner et al. (2009) found that temperature and aridity gradients served as major selective pressures in the adaptation of wild barley $(H$. vulgare ssp. spontaneum). This is confirmed by the on-site observations made by the second author of the present article during his germplasm explorations in five provinces in western Iran (see also Arzani and Ashraf 2016).

Photosynthesis as the most sensitive physiological process is significantly affected by heat stress (Wang et al. 2015). The reductions in $P_{\mathrm{N}}$ and $g_{\mathrm{s}}$ due to high temperature observed in the current study are generally consistent with those reported elsewhere on bread wheat (Gupta et al. 2015, Dwivedi et al. 2017). Under high temperatures, the ability to sustain leaf gas exchange is directly associated with heat tolerance in all plant species (Bita and Gerats 2013). The wild genotypes maintained their $g_{s}$ values under heat stress better than did the cultivated ones, indicating that the $\mathrm{H}_{2} \mathrm{O} / \mathrm{CO}_{2}$ exchange in the leaves of $H$. vulgare ssp. spontaneum is relatively less disturbed by high temperatures. It is argued that the increase in $C_{\mathrm{i}}$ under stress conditions may be more influenced by photosynthesis than by $g_{\mathrm{s}}$ (Feng et al. 2014). Since the initial targets of thermal damage are PSII and Rubisco, a large portion of the negative effect of high temperature on net photosynthesis is associated with decreased carbon fixation followed by net carbon assimilation in plants. Consequently, photosynthetic constraints due to high temperatures during the reproductive stage cause strict limitation on the availability of assimilates to the grains, thereby leading to reduced grain yield (Dwivedi et al. 2017). Nevertheless, the inverse relationship between photosynthetic rate and grain yield loss in our study can

Table 3. Direct and indirect effects of photosynthetic rate, stomatal conductance, $F_{v} / F_{m}$, chlorophyll and carotenoid contents, proline content and membrane stability index on grain yield loss of wild barley genotypes under heat stress during grain-filling stage. Chl chlorophyll; Car - carotenoids; $\mathrm{F}_{\mathrm{v}} / \mathrm{F}_{\mathrm{m}}$ - maximum quantum yield of PSII photochemistry; $g_{\mathrm{s}}-$ stomatal conductance; $\mathrm{MSI}-$ membrane stability index; $P_{\mathrm{N}}-$ net photosynthetic rate.

\begin{tabular}{lllllllll}
\hline Trait & $\begin{array}{l}\text { Direct } \\
\text { effects }\end{array}$ & $\begin{array}{l}\text { Indirect effects } \\
P_{\mathrm{N}}\end{array}$ & & & & & & \\
\\
\end{tabular}




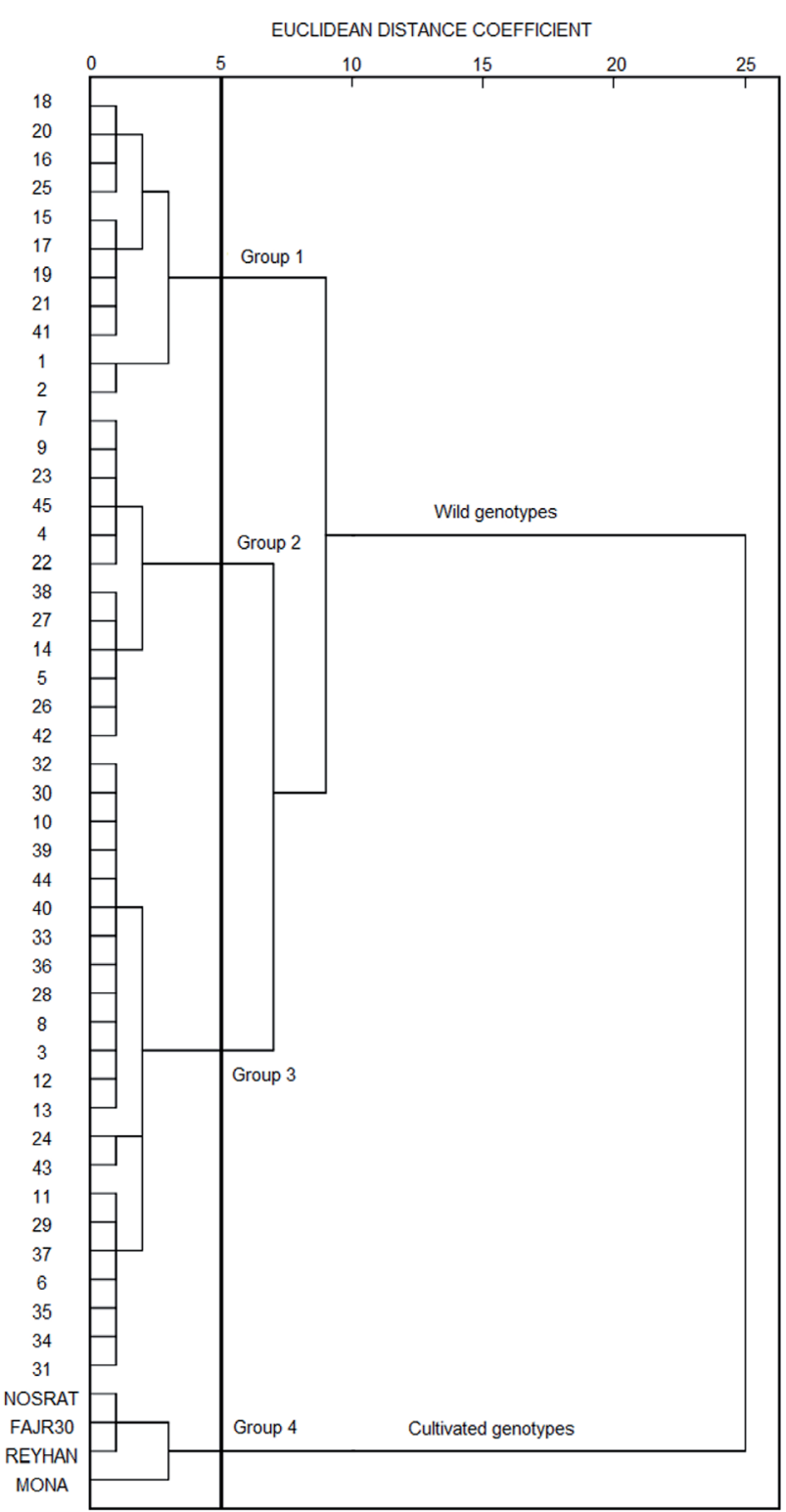

Fig. 3. Dendrogram generated for barley genotypes (Table 1S) based on grain yield loss, physiological traits and grain yield in barley genotypes under heat stress using Ward's method.

be explained by the negative effect of reduced $P_{\mathrm{N}}$ on grain yield under elevated temperatures.

Overall, the reduced photosynthetic electron transport under high temperatures can be attributed to the thermal stability of PSII (Brestic and Živčák 2013). According to our results, $\mathrm{F}_{\mathrm{m}}$ decreases under heat stress, while $\mathrm{F}_{0}$ increases. A similar trend was also observed in a previous study of ten varieties of barley (Oukarroum et al. 2016). Kalaji et al. (2011) suggested that the significant reduction in $\mathrm{F}_{\mathrm{m}}$ under heat stress is most likely caused by the inactivation of the oxygen-evolving complex in the PSII complex. The observed reduction in $\mathrm{F}_{\mathrm{v}} / \mathrm{F}_{\mathrm{m}}$ due to terminal heat stress is consistent with that reported by Sharma et al. (2015) for wheat cultivars exposed to heat stress during their grain-filling stage. The $F_{v} / F_{m}$ value is generally considered as a reliable criterion for evaluating the extent of damage caused by a given stress at the PSII complex, and the rate of photoprotective responses induced by the photosynthetic activity of the plants (Roháček et al. 2008, Brestic and Živčák 2013). The strong inverse relationship observed in the current study between $\mathrm{F}_{\mathrm{v}} / \mathrm{F}_{\mathrm{m}}$ and grain yield loss further supports for the idea that thermal stress may hamper the efficient absorption of light, the energy flow of the light captured, and the reaction center of photosynthetic systems in using light. Evaluating 30 winter wheat genotypes, Brestic et al. (2012) reported that the PSII thermostability of genotypes was associated with their origin and acclimation capacity. In addition, it has been shown that the ability to maintain an efficient photoprotection under high temperatures is crucial for heat tolerance (Sharkey and Zhang 2010, Brestic et al. 2016). Congruently, it is unfavorable that the cultivated barley genotypes are poorly protected and, thus, vulnerable to the stress when compared with the wild barley genotypes.

Leaf Chl, a vital pigment involved in light-harvesting and energy dissipating functions, was found to be negatively influenced by heat stress. It is interesting to note that although both the cultivated and wild barley genotypes exhibited close average values of the total Chl content under normal conditions, heat stress led to significantly lower Chl degradation in the wild barley than that in the cultivated ones. The strong inverse relationship observed between the total $\mathrm{Chl}$ and grain yield loss under heat stress provides further evidence that leaf $\mathrm{Chl}$ content can be exploited as an indicator of either plant photosynthetic capacity or its yield potential under thermal-stress conditions (Gupta et al. 2013, Wang et al. 2015). The reduced Chl content under heat stress could be explained by the reduced expression of Chl synthase (CS) gene as reported by Saha et al. (2016) for the $\mathrm{C}_{4}$ plant species Setaria viridis. Similar to our observations in barley, the reduced Car under heat stress (at temperatures above $35^{\circ} \mathrm{C}$ ) was reported for bread wheat (Sarkar et al. 2016) and durum wheat (Dias et al. 2011). The high correlation observed between Chl content and $P_{\mathrm{N}}$ under high temperatures may be caused by both the downregulation of Chl synthesis in the chloroplast and the accumulation of reactive oxygen species, which lead to Chl degradation in plants and the subsequently reduced $P_{\mathrm{N}}$ (Dwivedi et al. 2017).

The greater proline accumulation in the leaves of $H$. vulgare ssp. spontaneum wild genotypes observed in this study is in agreement with the finding of Gosavi et al. (2014) who reported higher proline contents accumulated in wild sorghum genotypes; such germplasm could be exploited in breeding programs for introgressing heat tolerance into cultivated sorghum.

Under heat stress, permeability enhancement and changes in cell differentiation and elongation as well as expansion of cellular membranes or thylakoids cause injuries to such cellular processes as photosynthesis and respiration via alterations in chloroplast proteins and the performance of ion channels (Kalaji et al. 2011, Bita and Gerats 2013). Thus, high temperatures increase the fluidity of membrane lipids and the subsequent loss of cellular membrane stability indicates the vital role of lipid 
membranes in response to heat stress in crops (Horváth et al. 2012). Our results were consistent with those of Dwivedi et al. (2017) who observed significant declines in the MSI values of both late and very late sown wheat cultivars due to high temperatures. In addition, linear regression results revealed not only the superiority of wild genotypes over domesticated ones with respect to steady maintenance of cell membrane integrity but also the perceived contribution of wild genotypes under heat stress. Nevertheless, changes in the environment bring about changes in the lipid composition of plasma membranes with tremendous effects on the functionality, sustained fluidity, and integrity of membranes, especially under stress conditions (Yeilaghi et al. 2012). The impact of heat stress on the composition of membranes, therefore, appears to be more damaging than other abiotic stresses because the fluidity of membranes composed of straightchain fatty acids can be easily disrupted by heat.

Heat tolerance is a complex trait related to the physiological and molecular bases of plant cells (Allakhverdiev et al. 2008). It seems difficult to dissect the photosynthetic regulatory mechanisms used by the wild barley to resist high temperatures (Brestic and Živčák 2013). However, the results of the current study suggest that the most important operations under heat stress is the control of the expression of genes involved in maintaining the functional properties of PSII, Chl contents, and cell membrane structure. In addition, it seems that the PSII thermostability and the stable cellular membrane structure observed in wild genotypes under heat stress can be related to their heat-tolerance genes including heatshock proteins (Hsps) which are both genetically and epigenetically regulated. Regarding domestication, the barley cultivars investigated exhibited higher grain yield means than that of the wild ones under both environmental conditions. Consequently, thermally tolerant genotypes were characterized by the lowest grain yield loss as a heat tolerance index followed by the highest values for $P_{\mathrm{N}}$, $\mathrm{F}_{\mathrm{v}} / \mathrm{F}_{\mathrm{m}}, \mathrm{MSI}$, Chl content, and proline content under terminal heat stress. The path-coefficient analysis carried out in this study revealed the relative importance of physiological traits for grain yield loss in the wild genotypes under terminal heat stresses at the grain-filling stage. Brestic et al. (2016) stated that high temperatures had a greater impact on $\mathrm{CO}_{2}$ assimilation capacity and photoprotection responses in wheat $\mathrm{Chl} b$-deficient mutant lines. Our results showed that, under high temperatures, the higher $\mathrm{Chl}$ content in the wild genotypes affected grain yield preservation at the grain-filling period either directly or indirectly through higher $P_{\mathrm{N}}$ and $\mathrm{F}_{\mathrm{v}} / \mathrm{F}_{\mathrm{m}}$. It is revealed that the performance of wild genotypes at the grain-filling stage is significantly associated with their maintenance of the functional photosynthetic apparatus under heat stress. Wang et al. (2015) used cluster analysis based on photosynthetic rates and grain yield to identify heat-tolerant wheat cultivars. Based on the grain yield and photosynthetic performance observed in the current study, 11 out of the 45 wild barley genotypes in the first group could be selected as superior wild genotypes for adaptation to climate changes brought about by heat. Furthermore, it is worth noting that the superior genotypes happened to originate from the southernmost province (i.e., Ilam) which is characterized by the hottest temperatures among the five provinces selected as the seed-collection sites.

Conclusion: The increasing temperature as a consequence of global climate change and the limited variability for heat tolerance in crop cultivars require reliable criteria to be established for screening thermal-tolerant wild germplasm. Given its wide distribution due to its high genome plasticity and, in particular, its heat-stressadapted germplasm from hot climatic regions, $H$. vulgare ssp. spontaneum may supply the ideal material for investigating climatic adaptations. Under field conditions, thermal-tolerant genotypes of $H$. spontaneum were found to employ various strategies to alleviate damages to their chlorophyll, cell membrane integrity, PSII, and photosynthetic rate. Considering the drastic effect of the global warming on the photosynthetic apparatus, the study of thermal-tolerant genotypes of wild barley can contribute tremendously to our understanding and improvement of carbon sequestration in cultivated barley by employing genetics and breeding tools.

\section{References}

Allakhverdiev S.I.: Recent progress in the studies of structure and function of Photosystem II. - J. Photoch. Photobio. B 104: 1-8, 2011.

Allakhverdiev S.I., Klimov V.V., Carpentier R.: Evidence for the involvement of cyclic electron transport in the protection of photosystem II against photoinhibition: Influence of a new phenolic compound. - Biochemistry 36: 4149-4154, 1997.

Allakhverdiev S.I., Kreslavski V.D., Klimov V.V. et al.: Heat stress: an overview of molecular responses in photosynthesis. - Photosynth. Res. 98:541-550, 2008.

Ashraf M., Harris P.J.C.: Photosynthesis under stressful environments: An overview. - Photosynthetica 51: 163-190, 2013.

Arzani A., Ashraf M.: Smart engineering of genetic resources for enhanced salinity tolerance in crop plants. - Crit. Rev. Plant Sci. 35: 146-189, 2016

Barnabás B., Jager K., Fehér A.: The effect of drought and heat stress on reproductive processes in cereals. - Plant Cell Environ. 31: 11-38, 2008.

Bates L.S., Waldren R.P., Teare I.D.: Rapid determination of free proline for water-stress studies. - Plant Soil 39: 205-207, 1973.

Bita C.E., Gerats T.: Plant tolerance to high temperature in a changing environment: scientific fundamentals and production of heat stress-tolerant crops. - Front. Plant Sci. 4: 273, 2013.

Brestic M., Živčák M.: PSII fluorescence techniques for measurement of drought and high temperature stress signal in plants: protocols and applications. - In: Rout G.R., Das A.B. (ed.): Molecular Stress Physiology of Plants. Pp. 87-131. Springer, Dordrecht 2013.

Brestic M., Živčák M., Kalaji H.M. et al.: Photosystem II thermostability in situ: environmentally induced acclimation and genotype-specific reactions in Triticum aestivum L. Plant Physiol. Bioch. 57: 93-105, 2012.

Brestic M., Živčák M., Kunderlikova K. et al.: High temperature specifically affects the photoprotective responses of chlorophyll $b$ deficient wheat mutant lines. - Photosynth. Res. 
130: 251-266, 2016.

Dias A.S., Semedo J., Ramalho J.C. et al.: Bread and durum wheat under heat stress: A comparative study on the photosynthetic performance. - J. Agron. Crop Sci. 197: 50-56, 2011.

Dhyani K., Ansari M.W., Rao Y.R. et al.: Comparative physiological response of wheat genotypes under terminal heat stress. - Plant Signal. Behav. 8: e24564, 2013.

Driedonks N., Rieu I., Vriezen W.H.: Breeding for plant heat tolerance at vegetative and reproductive stages. - Plant Reprod. 29: 67-79, 2016.

Dwivedi S.K., Basu S., Kumar S. et al.: Heat stress induced impairment of starch mobilization regulates pollen viability and grain yield in wheat: Study in Eastern Indo Gangetic Plains. - Field Crop. Res. 206: 106-114, 2017.

Feng B., Liu P., Li G. S. et al.: Effect of heat stress on the photosynthetic characteristics in flag leaves at the grain-filling stage of different heat-resistant winter wheat varieties. - J. Agron. Crop Sci. 200: 143-155, 2014.

Gosavi G.U., Jadhav A.S., Gadakh S.R. et al.: Effect of heat stress on proline, chlorophyll content, heat shock proteins and antioxidant enzyme activity in sorghum (Sorghum bicolor) at seedlings stage. - Indian J. Biotechnol. 13: 356-363, 2014.

Gupta N.K., Agarwal S., Agarwal V.P. et al.: Effect of short-term heat stress on growth, physiology and antioxidative defense system in wheat seedlings. - Acta Physiol. Plant. 35: 18371842, 2013.

Gupta N.K., Khan A., Maheshwari A. et al.: Effect of post anthesis high temperature stress on growth, physiology and antioxidative defense mechanisms in contrasting wheat genotypes. - Indian J. Plant Physiol. 20: 103-110, 2015.

Harlan J.R., Zohary D.: Distribution of wild wheats and barley. Science 153: 1074-1080, 1966.

Horváth I., Glatz A., Nakamoto H. et al.: Heat shock response in photosynthetic organisms: membrane and lipid connections. Prog. Lipid Res. 51: 208-220, 2012.

Hübner S., Höffken M., Oren E. et al.: Strong correlation of wild barley (Hordeum spontaneum) population structure with temperature and precipitation variation. - Mol. Ecol. 18: 1523-1536, 2009.

Jedmowski C., Ashoub A., Momtaz O. et al.: Impact of drought, heat, and their combination on chlorophyll fluorescence and yield of wild barley (Hordeum spontaneum). - J. Bot. 2015: 120868, 2015.

Kalaji H., Bosa K., Kościelniak J. et al:: Chlorophyll a fluorescence- a useful tool for the early detection of temperature stress in spring barley (Hordeum vulgare L.). Omics 15: 925-934, 2011.

Klink K., Wiersma J.J., Crawford C.J. et al.: Impacts of temperature and precipitation variability in the Northern Plains of the United States and Canada on the productivity of spring barley and oat. - Int. J. Climatol. 34: 2805-2818, 2014.

Lichtenthaler H.K., Wellburn A.R.: Determinations of total carotenoids and chlorophylls a and b of leaf extracts in different solvents. - Biochem. Soc. T. 11: 591-592, 1983.

Oukarroum A., Madidi S.E., Strasser R.J.: Differential heat sensitivity index in barley cultivars (Hordeum vulgare L.) monitored by chlorophyll a fluorescence OKJIP. - Plant Physiol. Bioch. 105: 102-108, 2016.
Ortiz R., Braun H.J., Crossa J. et al.: Wheat genetic resources enhancement by the International Maize and Wheat Improvement Center (CIMMYT). - Genet. Resour. Crop Evol. 55: 1095-1140, 2008.

Rezaei M., Arzani A., Sayed-Tabatabaei B.E.: Meiotic behaviour of tetraploid wheats (Triticum turgidum L.) and their synthetic hexaploid wheat derivates influenced by meiotic restitution and heat stress. - J. Genet. 89: 401-407, 2010.

Roháček K., Soukupová J., Barták M.: Chlorophyll fluorescence: a wonderful tool to study plant physiology and plant stress. - In: Schoefs B. (ed.): Plant Cell Compartments - Selected Topics. Pp. 64-66. Research Signpost, Trivandrum 2008.

Saha P., Sade N., Arzani A. et al. Effects of abiotic stress on physiological plasticity and water use of Setaria viridis (L.). Plant Sci. 251: 128-138, 2016.

Sairam R.K.: Effect of moisture stress on physiological activities of two contrasting wheat genotypes. - Indian J. Exp. Biol. 31: 551-553, 1994.

Sarkar J., Chakraborty B., Chakraborty U.: Temperature stress induced antioxidative and biochemical changes in wheat (Triticum aestivum L.) cultivars. - J. Plant Stress Physiol. 2: 22-30, 2016.

SAS/STAT User's Guide, Version 9.3 SAS Inst. Inc. Cary, NC 2011.

Schauberger B., Archontoulis S., Arneth A.: Consistent negative response of US crops to high temperatures in observations and crop models. - Nat. Commun. 8: 13931, 2017.

Sharkey T.D., Zhang R.: High temperature effects on electron and proton circuits of photosynthesis. - J. Integr. Plant Biol. 52: 712-722, 2010.

Sharma D.K., Andersen S.B., Ottosen C.O. et al.: Phenotyping of wheat cultivars for heat tolerance using chlorophyll $a$ fluorescence. - Funct. Plant Biol. 39: 936-947, 2012.

Sharma D.K., Andersen S.B., Ottosen C.O. et al.: Wheat cultivars selected for high $\mathrm{F}_{\mathrm{v}} / \mathrm{F}_{\mathrm{m}}$ under heat stress maintain high photosynthesis, total chlorophyll, stomatal conductance, transpiration and dry matter. - Physiol. Plantarum 153: 284298, 2015.

Shi P., Zhu Y., Tang L. et al.: Differential effects of temperature and duration of heat stress during anthesis and grain filling stages in rice. - Environ. Exp. Bot. 132: 28-41, 2016.

Thormann L., Reeves P., Reilley A. et al.: Geography of genetic structure in barley wild relative Hordeum vulgare subsp. spontaneum in Jordan. - PLoS ONE, 11: e160745, 2016.

Truong H.A., Jeong C.Y., Lee W.J. et al.: Evaluation of a rapid method for screening heat stress tolerance using three Korean wheat (Triticum aestivum L.) cultivars. - J. Agric. Food Chem. 65: 5589-5597, 2017.

Wahid A., Gelani S., Ashraf M. et al.: Heat tolerance in plants: An overview. - Environ. Exp. Bot. 61: 199-223, 2007.

Wang X., Dinler B.S., Vignjevic M. et al.: Physiological and proteome studies of responses to heat stress during grain filling in contrasting wheat cultivars. - Plant Sci. 230: 33-50, 2015.

Yeilaghi H., Arzani A., Ghaderian M. et al.: Effect of salinity on seed oil content and fatty acid composition of safflower (Carthamus tinctorius L.) genotypes. - Food Chem. 130: 618-625, 2012.

(C) The authors. This is an open access article distributed under the terms of the Creative Commons BY-NC-ND Licence. 